\section{A metodologia da história oral de vida como estratégia humanizadora de aproximação entre cuidador/idoso}

\author{
Oral life history as a humanistic strategy for the \\ approach between caregivers and the elderly
}

\author{
La metodología de la historia oral como \\ estrategia humanizadora de aproximación \\ entre cuidador/anciano
}

Carla Souza Mota 1

Valdir Reginato 1

Dante Marcello Claramonte Gallian 1
1 Centro de História e Filosofia das Ciências da Saúde, Universidade Federal de São Paulo, São Paulo Brasil.

Correspondência C. S. Mota

Centro de História e Filosofia das Ciências da Saúde, Universidade Federal de São Paulo.

Rua Rancharia 8, Santo André, SP 09230-240, Brasil. bebecarlinha@yahoo.com.br

\section{Abstract}

This study describes the use of oral life history as a strategy for the approach between caregivers and the elderly. The aim is to contribute to humanization of the relationship between health professionals and patients. A qualitative descriptive study included a sample of seven elderly individuals of both sexes and 65 years or older. Open, semi-structured interviews were conducted, producing narratives of the patients' life histories. The narratives were later returned to the participants in the form of personalized booklets for use as they saw fit. The approach contributed to the formation and strengthening of bonds between the nursing staff and the elderly and enhanced both the human and therapeutic aspects of this relationship.

Aged; Health of the Elderly; Humanization of Assistance; Life Change Events; Autobiography

\section{Resumo}

Este artigo objetiva apresentar um estudo sobre o uso da abordagem da História Oral de Vida como estratégia de aproximação entre cuidador e idoso, a fim de contribuir para a humanização na relação entre profissional da saúde $e$ paciente. Trata-se de uma pesquisa qualitativa e descritiva. Nossa amostra reuniu sete idosos, homens e mulheres, maiores de 65 anos que, por meio de entrevistas abertas e semiestruturadas, possibilitaram a produção de narrativas de histórias de vida, as quais, uma vez finalizadas, foram devolvidas aos colaboradores na forma de cadernos personalizados para que dispusessem delas como quisessem. Como resultado pôdese perceber que tal abordagem contribuiu para a geração e fortalecimento do vínculo entre enfermeiro e idoso, apresentando-se não apenas como elemento humanizador, mas também terapêutico.

Idoso; Saúde do Idoso; Humanização da Assistência; Acontecimentos que Mudam a Vida; Autobiografia 


\section{Introdução}

A vida prolonga com o progresso. $\mathrm{O}$ consequente envelhecimento, fenômeno universal, tem sido vivenciado diferentemente através da diversidade cultural, sem, porém, considerar a satisfação e desejos particulares, fundamentais para a qualidade de vida 1 . Contemporaneamente, a velhice que é considerada no âmbito basicamente biológico, é, quase sempre, vista como perda da capacidade produtiva ${ }^{2}$. Diante disso, é comum nos depararmos com uma assistência bem estruturada tecnicamente, porém deficitária do ponto de vista humanístico ${ }^{3}$.

As mudanças na dinâmica familiar moderna, associadas à precariedade do Sistema de Saúde, agravaram o "problema do idoso", determinando o aparecimento da figura do cuidador que, não necessariamente é um técnico da área da saúde, mas, o assiste nos cuidados das atividades cotidianas, tanto no domicílio como em instituições de longa permanência ${ }^{3}$. A formação do cuidador compreende os aspectos físicos do cuidado, porém exige também o aprimoramento da dimensão humana da relação cuidador/idoso, envolvendo as circunstâncias de ordem social e psicológica, que influem na promoção de uma abordagem mais humanizada 3 .

Contar histórias é uma tendência arraigada ao ser humano que se exacerba na senectude. Levar isso em consideração pode auxiliar muito no desenvolvimento de uma abordagem mais humanizada nas relações entre cuidador e idoso. As intervenções devem partir do princípio do ouvir com atenção e empatia, na intenção de compreender qual o significado atribuído a essa fase de suas vidas e como lidam com isso, apresentando-se, muitas vezes, como lenitivo da solidão 2,4 .

Segundo Bosi 5 , a narrativa não se detém na exposição de testemunhos objetivos e imparciais, mas os relaciona à convivência do orador aproximando-o do ouvinte e desempenhando um papel terapêutico ${ }^{5,6}$. Como bem pontua Halbwachs 7 , o recurso à narrativa do idoso pode ser um elemento privilegiado de resgate da identidade, na medida em que estabelece um intrincado entrelaçamento entre a memória individual e a memória coletiva.

O objetivo deste estudo foi verificar em que medida a História Oral de Vida ${ }^{8}$ pode constituir um recurso de aproximação entre cuidador e idosos e apresentar-se como alternativa - mais humanizada - às práticas individualistas que excluem o idoso do seu histórico de vida 9.

\section{Metodologia}

Trata-se de uma pesquisa qualitativa, utilizandose a História Oral de Vida como metodologia. Essa consiste na arte de apreender narrativas a fim de obter material para conhecimento e análise de um determinado processo social do presente, favorecendo não apenas os estudos de identidade, mas também de toda a memória de uma cultura 7,10 .

Foram entrevistados sete idosos, quatro mulheres e três homens em 2010. Cinco desses idosos residiam em instituições de longa permanência, outros dois, em domicílio. Cada participante concedeu duas entrevistas, que foram abertas e não diretivas e visaram a suscitar um relato amplo e livre da trajetória de vida dos entrevistados, conforme as diretrizes preconizadas pelo método ${ }^{8}$.

As entrevistas foram transcritas e submetidas à transcrição, processo em que são transformadas num relato literário em primeira pessoa, conferidas e aprovadas pelos entrevistados. Para o registro das reações, considerações e avaliação do processo utilizou-se o recurso do caderno de campo ${ }^{8}$. As narrativas foram editadas na forma de um caderno personalizado, destacando na capa um desenho e o "tom vital", que é uma frase ou palavra que sintetiza a narrativa ${ }^{8}$. Cópias foram dadas aos entrevistados para que pudessem presentear a quem quisessem.

O projeto foi aprovado pelo Comitê de Ética em Pesquisa da UNIFESP (protocolo CEP no 0370/10).

\section{Resultados e discussão}

A memória, coletiva e individual, ocupa um lugar central na dimensão da identidade da pessoa idosa 5,7. O fato de que a estruturação da identidade advém da memória correlaciona a importância dos relatos narrativos com a promoção da saúde. Por sua vez, a desumanização vincula-se ao desaparecimento da capacidade de narrar, comprometendo a dignidade da pessoa ao negligenciar a dimensão mais essencial da identidade, a experiência vivida 11 .

As narrativas na abordagem da História Oral de Vida revelaram como o idoso, alijado da sociedade por uma dinâmica perversa de marginalização, experimenta o esquecimento por parte do "mundo jovem e produtivo", e sofre a influência em suas condições de saúde. Demonstram que o isolamento e a solidão superam as limitações físicas, pelas diversas enfermidades, como causas de maior tristeza e sofrimento. 
O primeiro efeito é colaborar no âmbito terapêutico conforme apontado por alguns autores ${ }^{8}$. Em quase todas as falas ocorre a "experiência de alívio", de "libertação", de uma memória "petrificada", silenciosa e solitária, fonte de dor e sofrimento, manifestada em doença 5 . A narrativa revela intimidades, sobretudo da representação pessoal acerca da vida (com particularidades desconhecidas até pelos familiares), transformando o cuidador ou profissional de saúde num possível interlocutor e destinatário de vínculos. A experiência, valorizada nos fatos mais simples, promove o idoso acima do patamar dos considerados "jovens", transformandoos em exemplos que dignificam a vida, provocando admiração e afeto pelos que os ouve.

Verificou-se uma diversidade incrível nas experiências vividas por pessoas que compartilharam a mesma época, emergindo uma visão de mundo 12 . A seguir, um breve perfil dos participantes, indicados pela letra maiúscula E, que significa entrevistado(a), enumerados conforme a ordem de execução.

E1 protegeu-se do bombardeio dentro de túneis. Hoje, é o elo mais forte que une sua família espalhada por diversos países. E2 demonstrou que não há idade para iniciar uma grande amizade. E3 revelou garra para sustentar seis crianças e viveu mais de 100 anos para ensinar a todos sobre sua fé. E4, com toda sua graciosidade, contou que todos nós queremos voltar à nossa casa e que isto pode significar a melhor época de nossas vidas e a fase mais significativa de nossa memória. E5 mostrou como a sociedade julga o comportamento, e a difícil credibilidade de que alguém possa ser digno de perdão e queira recomeçar mesmo aos 60 anos. E6 deu uma lição de amor e caráter ao tentar garantir a situação financeira de sua ex-mulher, após seu falecimento. E7 tinha uma forma de encarar a vida que poderia servir às diversas pessoas que temem o envelhecimento.

Mergulhando em suas próprias histórias, com muita expressividade, sentiam como se revivessem o momento descrito. Temas existenciais como a morte, que habitualmente inquietam o ser humano, assim como os profissionais da saúde e cuidadores, são narrados naturalmente. Os aspectos positivos causavam riso e um gosto de "quero mais"; os negativos tornavam-se um desafio à implementação de uma abordagem humanizada. Aprimora-se o cuidado com humanização, não só preservando a dignidade do idoso, vinculada aos cuidados cotidianos, mas oferecendo a oportunidade de crescimento por meio da fala e da escuta 3 .
Proporcionar o exercício da memória que permite reviver aquilo que teve maior significado em sua vida, seus maiores prazeres e felicidades, favorece o acolhimento quando se ouve acompanhado de um sorriso. A humanização está em celebrar suas conquistas, individuais e coletivas, as quais representam benefícios a toda sociedade, destruindo o estereótipo de que o idoso é um corpo enfermo que terminará seus dias dentro de uma instituição 13 .

A enfermagem quando prioriza as novas tecnologias em detrimento do cuidado compromete a qualidade do atendimento ${ }^{14}$. A comprovação se dá pelo fato de as instituições asilares não servirem como modelo gerador da melhor qualidade de vida, apesar do compromisso com a eficiência enfocando os aspectos humanísticos ao idoso 15 .

Na busca contínua de um melhor atendimento, este projeto mostra que os afazeres diários não devem sufocar nossa alma e coração e enterrar a sensibilidade de ver muito além das aparências. Substituir o olhar e a escuta atentos pela ação isolada de procedimentos técnicos, imprescindíveis, gera o que caracteriza uma cultura desumanizada.

A ideia de que quando aparentemente não há nada a fazer ainda podemos ouvir 4 ficou clara com a abordagem da História Oral de Vida, que com toda a sua dinâmica de colaboração, acabou por se mostrar um caminho de criação de vínculo e de aproximação que, seguramente, torna concreta e efetiva a humanização do cuidado.

\section{Conclusões}

A narrativa, uma ferramenta tão simples na prática e isenta de recursos financeiros, revelou-se tão complexa e carregada de valores que ninguém permanece o mesmo depois desta experiência, nem o ouvinte e nem o narrador. A narrativa é responsável por humanizar a pessoa, individualizando-a, pois declara sua memória única, em períodos fascinantes da vida, contribuindo para mostrar o quanto ela é importante como ser humano.

A História Oral de Vida mostrou-se um instrumento extremamente interessante a ser utilizado para uma abordagem que colabore na aproximação e criação de vínculo entre cuidador ou profissional de saúde (entrevistador) e aquele que é cuidado (entrevistado). 


\section{Resumen}

El objetivo de este artículo es presentar un estudio sobre el uso de la historia oral de vida como estrategia de aproximación entre cuidador y anciano, con el fin de contribuir a la humanización en la relación entre el profesional de la salud y el paciente. Se trata de una investigación cualitativa y descriptiva. Hemos reunido a siete ancianos, varones y mujeres, con más de 65 años que, a partir de entrevistas abiertas y semi-estructuradas, hicieron posible la producción de relatos de vida que, una vez finalizados, fueron devueltos a los colaboradores en forma de cuadernos personalizados para que ellos dispusieran de ellos como quisieran. Como resultado ha sido posible percibir que tal metodología contribuye a la generación de un vínculo entre enfermero y anciano, presentándose no solamente como elemento humanizador, sino también terapéutico.

Anciano; Salud del Anciano; Humanización de la Atención; Acontecimientos que Cambian la Vida; Autobiografía

\section{Colaboradores}

C. S. Mota contribuiu para a concepção, design, aquisição, análise e interpretação de dados. V. Reginato foi responsável pela redação do artigo e revisão crítica do conteúdo intelectual. D. M. C. Gallian foi responsável pela redação, revisão crítica e aprovação da versão do artigo a ser publicada

\section{Agradecimentos}

Os autores agradecem ao CNPq (processo no 111925 / 2010-0) pelo financiamento da pesquisa e pela bolsa de produtividade de C. S. Mota. Agradecemos aos idosos e suas famílias que permitiram chegar ao nosso conhecimento as mais belas histórias de vida, sem eles este trabalho não seria possível.

\section{Referências}

1. Ribeiro CDM, Schramm FR. Como equacionar a desejável frugalidade e a necessidade de proteção na saúde do idoso? Cad Saúde Pública 2004; 20:1157-9.

2. Uchôa E. Contribuições da antropologia para uma abordagem das questões relativas à saúde do idoso. Cad Saúde Pública 2003; 19:849-53.

3. Bertachini L, Pessini L. Humanização e cuidados paliativos. São Paulo: Edições Loyola; 2004.

4. Benedetto MAC, Blasco PG, Levittes M, Pinheiro TR. Narrativas em cuidados paliativos: um instrumento para lidar com a dor, o sofrimento e a morte. Revista Brasileira de Cuidados Paliativos 2009; 2:16-20.

5. Bosi E. Memória e sociedade: lembranças de velhos. São Paulo: Companhia das Letras; 1994.

6. Silva DGV, Trentini M. Narrativas como técnica de pesquisa em enfermagem. Rev Latinoam Enferm 2002; 10:423-32.

7. Halbwachs M. Memória individual e memória coletiva. In: Halbwachs M, organizador. A memória coletiva. São Paulo: Centauro Editora; 2006. p. 2970 .

8. Meihy JCSB, Holanda F. História oral: como fazer como pensar. São Paulo: Contexto Editora; 2007.

9. Camacho ACLF. A gerontologia e a interdisciplinaridade: aspectos relevantes para a enfermagem. Rev Latinoam Enferm 2002; 10:229-33.
10. Meihy JCSB. Manual de história oral. São Paulo: Edições Loyola; 2005.

11. Benjamin W. O narrador. Considerações sobre a obra de Nikolai Leskov. In: Benjamin W, organizador. Magia e técnica, arte e política; ensaios sobre literatura e história da cultura. Obras Escolhidas. v. 1. São Paulo: Editora Brasiliense; 1987. p. 197-221.

12. Bosi E. O tempo vivo da memória: ensaios de psicologia social. São Paulo: Ateliê Editorial; 2003.

13. Orb A. Aspectos de salud en adultos mayores de 80 anos de edad que viven independientemente en la comunidad: una perspectiva australiana. Rev Latinoam Enferm 2004; 12:589-96.

14. Brum AKR, Tocantins FR, Silva TJES. O enfermeiro como instrumento de ação no cuidar do idoso. Rev Latinoam Enferm 2005; 13:1019-26.

15. Duarte MJRS. Autocuidado para a qualidade de vida. In: Caldas CP, organizador. A saúde do idoso: a arte de cuidar. Rio de Janeiro: EdUERJ; 1998. p. 17-34.

Recebido 15/Jan/2013

Versão final reapresentada em 16/Abr/2013

Aprovado em 29/Abr/2013 